\title{
Severe Rheumatic Mitral Stenosis in Marfanoid Young Man Successfully Managed with Percutaneous Mitral Balloon Valuotomy
}

\section{JCR}

\author{
Premchand Rajendra Kumar, Geetesh Manik, Mohammed Sadiq Azam \\ Department of Cardiology, Krishna Institute of Medical Sciences, Secunderabad, \\ Telangana, India.
}

\begin{abstract}
:
Rheumatic heart disease (RHD) has a prevalence of 0.2 to $1.1 / 1000$ in India. $25 \%$ patients with RHD develop mitral stenosis (MS). Marfan's syndrome (MFS) is an autosomal dominant inherited defect in the FBN1 gene coding for fibrillin. Skeletal and cardiovascular involvement is common. Mitral valve prolapse or mitral regurgitation is common while mitral stenosis is seldom associated with MFS. Our patient had a rare combination of marfanoid habitus and severe rheumatic mitral stenosis (MS) which to the best of our knowledge has been scarcely reported. When indicated as per guidelines, percutaneous mitral balloon valvotomy (PBMV) is the procedure of choice for MS. MFS patients have a high genetic propensity towards developing MR and hence a PBMV would be associated with a high risk of MR. Our case was successfully managed with PBMV with good symptomatic relief and no post-procedural MR.
\end{abstract}

Key words: Balloon Valvuloplasty, Cardiac Surgical Procedures, Heart Valves, Marfan Syndrome, Mitral Valve Stenosis.

\section{Introduction}

Marfan's syndrome (MFS) is an autosomal dominant inherited disorder due to defect in the FBN1 gene on chromosome 15 that codes for the connective tissue protein fibrillin. It is characterised by multisystem pathologies of which skeletal and cardiovascular involvement are most common. Skeletal manifestations include arachnodactyly, dolichostenomelia, pectus deformities and thoracolumbar scoliosis. The most common cardiovascular involvement reported is aortic root dilatation and mitral valve prolapse (MVP). In our review of literature we came across a single other case report of rheumatic mitral stenosis in a patient with MFS [1].

\section{Case Report}

A 28 year old gentleman presented to the cardiology outpatient department with complaints of breathlessness on less than usual exertion since 2 weeks. His symptoms started about 3 years ago when he first noticed getting breathless while doing his routine activity which led to impairment in

\section{Corresponding Author: Dr. Geetesh Manik}

Email: geetesh.manik@gmail.com

Received: May 3, 2016 | Accepted: June 7, 2016 | Published Online: July 25, 2016

This is an Open Access article distributed under the terms of the Creative Commons Attribution License (creativecommons.org/licenses/by/3.0)

Conflict of interest: None declared | Source of funding: Nil | DOl: http://dx.doi.org/10.17659/01.2016.0083 
performing daily tasks. Since past 1 week he has had episodes suggestive of paroxysmal nocturnal dyspnea which prompted him to seek medical attention. Head to foot examination revealed a marfanoid habitus as he was extremely thin built with loss of skeletal muscle mass, pectus carinatum, high arched palate, height of $172 \mathrm{~cm}$ and an arm span of $195 \mathrm{~cm}$ (arm span to height ratio of 1.13) [Fig.1] and a reduced upper segment to lower segment ratio of 0.72 , and arachnodactyly as evidenced by a positive wrist and thumb (Steinberg) sign [Fig.2]. His father also had a similar habitus on examination.

\section{Cardiovascular system examination} revealed an elevated jugular venous pressure, regular heart rate of 98 beats per minute, blood pressure of $110 / 70 \mathrm{mmHg}$ with no significant difference in pulses or pressure between all 4 limbs. A loud first heart sound with a high pitched opening snap and a long, rough and rumbling, low pitched mid diastolic murmur with presystolic accentuation and short A2-OS interval, with loud pulmonary component of the second heart sound was noted, suggestive of severe mitral stenosis with pulmonary hypertension. There were no other skeletal or ocular abnormalities seen in this patient. Transthoracic echocardiogram confirmed the diagnosis of severe rheumatic mitral stenosis (Mitral valve area by planimetery: $0.931 \mathrm{~cm}^{2}$ ) [Fig.3] with pulmonary hypertension (RVSP $73 \mathrm{mmHg}$ ).

No other valve or aortic abnormality was found on echocardiography. After hemodynamic stabilisation, a transesophageal echocardiogram was done to rule out a left atrial clot and calculate the Wilkins' score which was 8/12. Patient was taken up for percutaneous balloon mitral valvotomy (PBMV). PBMV was done [Fig.4] with good result following which patient improved symptomatically and was discharged in a stable condition.

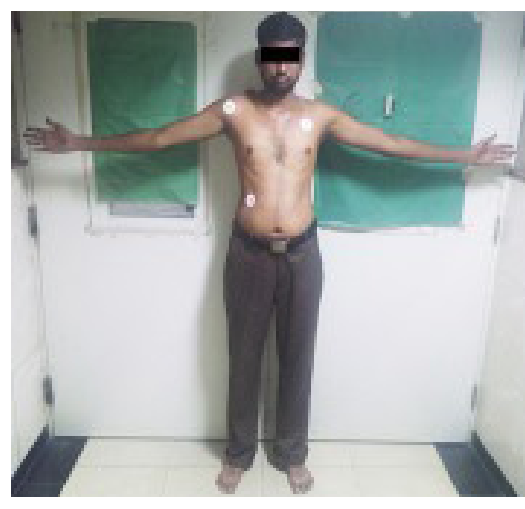

Fig.1: Patient with outstretched arms demonstrating dolichostenomelia (arm span greater than the height of the individual).

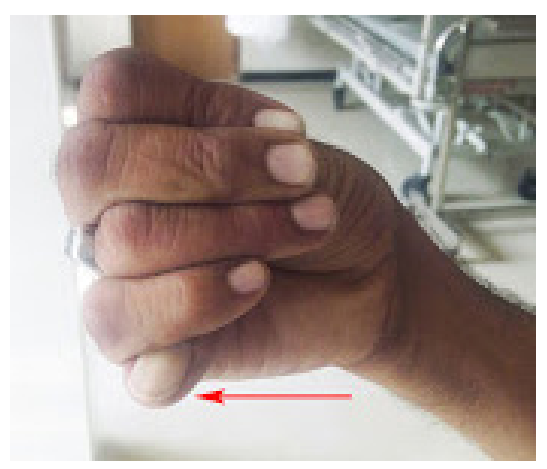

Fig.2: Patient's clenched fist showing a positive thumb (Steinberg) sign suggestive of arachnodactyly.

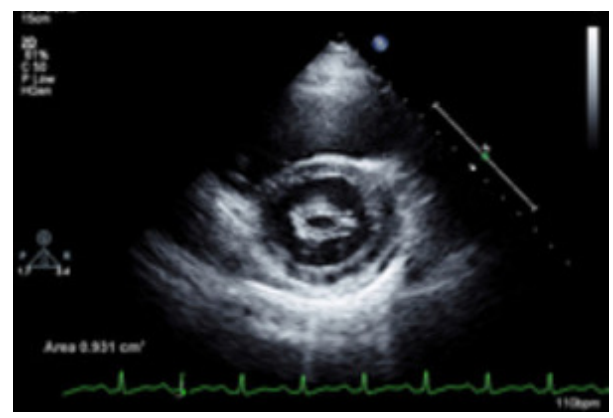

Fig.3: Echocardiographic short axis (SAX) view at level of mitral valve showing a mitral valve area of $0.931 \mathrm{~cm}^{2}$ by planimetry indicating severe mitral stenosis. 


\section{Discussion}

Marfan's syndrome (MFS) is named after Antonin Bernard Jean Marfan who first described the disease in 1896 in 5-year-old girl named Gabrielle, who had disproportionately long limbs [2]. MFS is a heritable connective tissue defect with an autosomal dominant transmission isolated to the FBN1 gene on chromosome 15 which codes for the protein fibrillin [3]. Abnormalities in fibrillin cause multisystem involvement, of which the musculoskeletal, cardiac, and ocular systems are most affected. MFS is currently diagnosed based on the Ghent criteria based on Marfanoid phenotype, family history and molecular studies to identify mutations in the FBN1 gene and other relevant genes such as TGFbR $1 / 2$, COL3A1, and ACTA2 [4]. Family history in a first degree relative is also included as a major criterion. Dolichostenomelia is seen in majority of the cases with MFS with an arm span-to-height ratio greater than 1.05 and a reduced upper-to-lower body segment ratio less than 0.85 .

Cardiovascular system involvement is a major cause of mortality and morbidity. The most common involvement is aortic root dilatation and mitral valve prolapse (MVP). The reported prevalence of aortic dilatation is $76 \%, \mathrm{MVP}$ is $62 \%$, mitral valve regurgitation is $29 \%$ and aortic regurgitation is $26 \%$, in adult patients with MFS. MVP is the commonest cardiac lesion present in adolescents with MFS [5]. Aortic dissection, chordal rupture leading to acute mitral regurgitation and heart failure, systolic and diastolic ventricular dysfunction, cardiomyopathy without valvular involvement have all been reported in MFS [6]. In our review of world literature we came across only a single reported case of rheumatic mitral stenosis in association with MFS [1].

Rheumatic heart disease (RHD) has been reported in a recent Indian Council of Medical Research (ICMR) study (between 2000 and 2010)

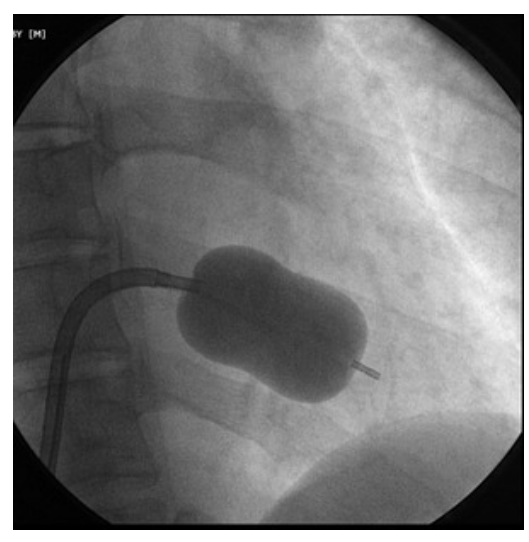

Fig.4: Fluroscopic image in RAO projection showing an inflated balloon across the mitral valve during PBMV procedure.

in 10 different, mostly urban, locations to have a prevalence ranging from 0.2 to $1.1 / 1000$ [7]. Pure mitral stenosis (MS) is seen in approximately $25 \%$ of all patients with rheumatic heart disease and an additional $40 \%$ have combined $M S$ and mitral regurgitation (MR) [8]. BMV is indicated in moderate or severe MS patients without the presence of left atrial thrombus or moderate to severe MR who are: (a) symptomatic (NYHA functional class II, III, or IV) with valve morphology favourable for PBMV; (b) asymptomatic who have pulmonary hypertension (pulmonary artery systolic pressure greater than $50 \mathrm{~mm} \mathrm{Hg}$ at rest or greater than $60 \mathrm{~mm} \mathrm{Hg}$ with exercise; (c) symptomatic patients who are either not candidates for surgery or are at high risk for surgery [9]. One of the major procedural complications with PBMV is the development of postprocedural MR. Due to the high genetic propensity of development of MR in cases with MFS [10]; PBMV has to be undertaken with utmost caution with careful planning and execution. It is also prudent to evaluate the aortic root for dilatation and valve abnormality which if present may warrant a single surgical procedure to address both the aortic and mitral defects. Our case had an isolated involvement of the mitral valve in the form of rheumatic mitral stenosis with echocardiographic features suggestive 
of a favourable valve for PBMV and he had a good result with significant drop in gradient and no $M R$ post-procedure. He had good symptomatic relief and is now on regular follow up.

\section{References}

1. Nagesh, $C M$, Patra $S$, Singh $A$, Badnur $S$ C, Reddy B, Nanjappa MC. A patient with Marfan's syndrome presented with severe rheumatic mitral stenosis and successfully treated with percutaneous transmitral balloon commissurotomy - Report of first case. Journal of Cardiovascular Disease Research. 2013;4(4):257-259.

2. Antoine $M$. Un cas de déformation congénitale des quartre membres, plus prononcée aux extrémitiés, caractérisée par l'allongement des os avec uncertain degré d'amincissement" [A case of congenital deformation of the four limbs, more pronounced at the extremities, characterized by elongation of the bones with some degree of thinning]. Bulletins et memoires de la Société medicale des hôspitaux de Paris 13 ( $3^{\text {rd }}$ series): $220-226$.

3. Dietz HC, Loeys B, Carta L, Ramirez F. Recent progress towards a molecular understanding of Marfan syndrome. Am J Med Genet C Semin Med Genet. 2005;139C(1):4-9.

4. Loeys BL, Dietz HC, Braverman AC, Callewaert
BL, De Backer J, Devereux RB, et al. The revised Ghent nosology for the Marfan syndrome. J Med Genet. 2010;47(7):476-485.

5. Porciani MC, Attanasio $M$, Lepri $V$, et al. Prevalence of cardiovascular manifestations in Marfan syndrome. Ital Heart J Suppl. 2004;5:647e652.

6. Alpendurada F, Wong J, Kiotsekoglou A, Banya W, Child A, Prasad SK, et al. Evidence for Marfan cardiomyopathy. Eur J Heart Fail. 2010;12:1085e1091.

7. Shah B, Sharma $M$, Kumar R, Brahmadathan KN, Abraham VJ, Tandon R. Rheumatic heart disease: Progress and challenges in India. Indian J Pediatr. 2013;80(Suppl 1):77-86.

8. Schoen EJ, St John Sutton M. Contemporary pathologic considerations in valvular heart disease. In: Virmani R, Atkinson JB, Feuglio JJ. Cardiovascular pathology. Philadelhia, WB saunders Co, 1991 ,pp.334.

9. ACC/AHA 2006 Guidelines for the Management of Patients with Valvular Heart Disease. A Report of the American College of Cardiology/American Heart Association Task Force on Practice Guidelines. J Am Coll Cardiol. 2006;48:1-148.

10. De Backer J. Cardiovascular characteristics in Marfan syndrome and their relation to the genotype. Verh K Acad Geneeskd Belg. $2009 ; 71: 335 \mathrm{e} 371$. 